\title{
Marie-Agnès Sourieau, Kathleen M. Balutansky (a cura di), Écrire en pays assiégé
}

\section{Anusca Ferrari}

\section{(2) OpenEdition}

1 Journals

\section{Édition électronique}

URL : http://journals.openedition.org/studifrancesi/33836

DOI : 10.4000/studifrancesi.33836

ISSN : 2421-5856

Éditeur

Rosenberg \& Sellier

\section{Édition imprimée}

Date de publication : 1 décembre 2005

Pagination : 688

ISSN : 0039-2944

\section{Référence électronique}

Anusca Ferrari, « Marie-Agnès Sourieau, Kathleen M. Balutansky (a cura di), Écrire en pays assiégé », Studi Francesi [En ligne], 147 (XLX | III) | 2005, mis en ligne le 30 novembre 2015, consulté le 20 avril 2021. URL : http://journals.openedition.org/studifrancesi/33836 ; DOI : https://doi.org/10.4000/ studifrancesi.33836

Ce document a été généré automatiquement le 20 avril 2021.

\section{(c)}

Studi Francesi è distribuita con Licenza Creative Commons Attribuzione - Non commerciale - Non opere derivate 4.0 Internazionale. 


\title{
Marie-Agnès Sourieau, Kathleen M. Balutansky (a cura di), Écrire en pays assiégé
}

\author{
Anusca Ferrari
}

\section{RÉFÉRENCE}

MARIE-AGNÈS SOURIEAU, KATHLEEN M. BALUTANSKY (a cura di), Écrire en pays assiégé. Haïti.

Writing under siege, Amsterdam-New York, Rodopi, 2004 («Francopolyphonies»), pp. 545.

1 Rarement un recueil d'essais nous a paru tellement captivant aussi bien du point de vue du contenu que de celui du paratexte. L'image en couverture, la structure et les annexes rendent ce livre alléchant avant la lecture. Le titre, ainsi que l'introduction, les résumés des articles et les introductions à chaque partie, sont rédigés en français et en anglais, donnant la possibilité d'approcher rapidement tous les essais de ce recueil, dont huit sont en anglais et douze en français. En couverture un tableau de Myrabel, L'union fait la force (2003), nous conduit vers le thème principal de l'œuvre, notamment l'état de siège de Haïti et ses conséquences sur la production artistique. Parmi les annexes, le plus utile nous parait la bibliographie, classée par auteur, de la production littéraire haïtienne, qui fournit aussi les traductions en anglais des œuvres principales, et dont le seul défaut, nous semble-t-il, est d'avoir oublié Dany Laferrière, qui est pourtant objet d'un des articles. Après la biographie des contributeurs, en français, on trouve une brève explication du tableau en couverture, et enfin un index des noms.

2 Le contenu n'est pas décevant: la diversité des essais construit un cadre d'ensemble complexe et structuré qui offre un apport substantiel à la critique sur la littérature haïtienne. Après un premier article introductif sur le pavillon haïtien à l'exposition de 1893 à Chicago, le livre se divise en trois parties, dont les thèmes sont respectivement le siège, la terreur et l'exil. La première examine la critique sociale et politique dans l'écriture haïtienne, avec six articles, portant sur la lodyans («l'audience», genre 
littéraire bref), Gouverneurs de la rosée de Jacques Roumain, l'œuvre romanesque de Jacques Stephen Alexis, l'itinéraire littéraire de Roger Dorsinville, un entretien avec René Depestre, et l'œuvre d'une femme-écrivain engagée comme Yanick Lahens. Dans la deuxième partie, centrée sur la période duvaliériste, les articles touchent les écoles littéraires nées sous le régime des Duvalier, le mouvement du Spiralisme, un entretien avec Frankétienne, Mémoire d'un amnésique de Jan Dominique, l'écriture féminine et les romans de Lyonel Trouillot. La troisième partie traite le corpus des auteurs exilés, à savoir Mimi Barthélémy, Jean Métellus (entretien), Émile Ollivier, Gérard Étienne, Dany Laferrière et Edwige Danticat. Enfin, un article sur le rôle de la mémoire dans l'écriture conclut le recueil.

3 Cette anthologie critique offre au lecteur une considérable source d'information et d'approfondissement sur plusieurs aspects de la littérature haïtienne. Pendant la lecture on oublie parfois le thème principal de l'ouvrage, qui est censé repérer les aspects de critique sociale de cette littérature. Mais chaque article, même les plus éloignés de l'optique politique, présente en fait la valeur de contre-discours de la littérature haïtienne, qui se manifeste dans toutes les facettes de sa production. 